\title{
The value of self-report assessment of adherence, rhinitis and smoking in relation to asthma control
}

\author{
Jane Clatworthy ${ }^{a}$, David Price ${ }^{b}$, Dermot Ryan ${ }^{b}$, John Haughney', *Rob Horne \\ a Centre for Behavioural Medicine, Department of Practice and Policy, The School of Pharmacy, University of London, BMA House, London, UK \\ ${ }^{\mathrm{b}}$ Department of General Practice and Primary Care, University of Aberdeen, Foresterhill Health Centre, Aberdeen, UK
}

Received 2nd October 2008; revised version received 9th February 2009; accepted 19th March 2009; online 26th June 2009

\begin{abstract}
Aims: To explore the utility of self-report measures of inhaled corticosteroid (ICS) adherence, degree of rhinitis and smoking status and their association with asthma control.

Methods: Patients prescribed ICS for asthma at 85 UK practices were sent validated questionnaire measures of control (Asthma Control Questionnaire; $A C Q$ ) and adherence (Medication Adherence Report Scale), a two-item measure of smoking status, and a single-item measure of rhinitis.

Results: Complete anonymised questionnaires were available for 3916 participants. Poor asthma control (ACQ $\geq 1.5)$ was associated with reported rhinitis $(\mathrm{OR}=4.62 ; 95 \% \mathrm{Cl}: 3.71-5.77)$, smoking $(\mathrm{OR}=4.33 ; 95 \% \mathrm{Cl}: 3.58-5.23)$ and low adherence to ICS (OR $=1.35 ; 95 \%$ $\mathrm{Cl}$ : 1.18-1.55). The degree of rhinitis was important, with those reporting severe rhinitis exhibiting the worst asthma control, followed by those reporting mild rhinitis and then those reporting no rhinitis symptoms $(F(2,3913)=128.7, p<.001)$. There was a relationship between the number of cigarettes smoked each day and asthma control $(F(5,655)=6.08, p<.001)$.

Conclusions: Poor asthma control is associated with self-reported rhinitis, smoking and low medication adherence. These potentially modifiable predictors of poor asthma control can be identified through a brief self-report questionnaire, used routinely as part of an asthma review.

(C) 2009 General Practice Airways Group. All rights reserved.

J Clatworthy et al. Prim Care Resp J 2009; 18(4): 300-305

doi:10.4104/pcrj.2009.00037
\end{abstract}

Keywords asthma, control, rhinitis, smoking, compliance, adherence

\section{Introduction}

The aim of asthma management is to achieve and maintain control of asthma - characterised by minimal or no symptoms, no emergency visits to physicians or hospitals, minimal need for reliever medications, no limitations on normal activities, nearly normal lung function, and minimal or no side-effects from medication. ${ }^{1,2}$ Large, multi-national, population-based studies suggest, however, that a minority of adults with asthma achieve good control, ${ }^{3-5}$ with one recent European study reporting that only $15 \%$ of adults prescribed inhaled corticosteroids (ICS) have completely controlled symptoms. ${ }^{6}$ The cost of poor control is high, both in terms of the patient's quality of life ${ }^{7.8}$ and demand on healthcare resources. ${ }^{9.12}$ It is therefore important to identify current asthma control and address modifiable determinants of poor control where it exists.

The International Primary Care Respiratory Group (IPCRG) has suggested an approach to asthma control based on establishing control and identifying clinical and behavioural factors associated with poor control. ${ }^{13}$ Clinical factors include medication triggers (e.g. aspirin, beta-blockers) ${ }^{14-16}$ and comorbid conditions such as allergic rhinitis ${ }^{17,18}$ and obesity. ${ }^{19,20}$ Behavioural factors include non-adherence, ${ }^{21,22}$ poor inhaler technique ${ }^{20,23,24}$ and smoking. ${ }^{25-28}$

If modifiable determinants of poor control can be identified in routine practice, they can be addressed in order to improve asthma control. The aim of this study therefore

\footnotetext{
* Corresponding author: Professor Rob Horne, Centre for Behavioural Medicine, Department of Practice and Policy, The School of Pharmacy, University of London, Mezzanine Floor, BMA House, Tavistock Square, London, WC1H 9JP, United Kingdom.

Tel: +44 (0) 2078741293 Fax: +44 (0) 2073875693 E-mail: rob.horne@pharmacy.ac.uk
} 
was to assess the association of simple self-report measures of adherence, rhinitis and smoking with asthma control.

\section{Methods \\ Design and sample}

This was a cross-sectional survey of asthma patients participating in a questionnaire-based audit of asthma control in 85 UK general practices. The practices were selected to be representative of UK general practice. They were situated across England $(n=67)$, Wales $(n=9)$, Scotland $(n=5)$ and Northern Ireland $(n=4)$.

\section{Procedure}

The general practices identified from their practice computer systems all those patients prescribed asthma treatment at Step 2 and above who were eligible for a questionnaire-based review of their asthma control. Inclusion criteria were adults (over 18 years of age) who were prescribed ICS for physiciandiagnosed asthma. These patients were sent a questionnaire by their GP, with a stamped addressed envelope for its return. Routine clinical and demographic data were downloaded from the practice database (e.g. age, gender, prescribed medications). Ethics approval for analysis of the anonymised audit data was obtained from the Optimum Patient Care (OPC) Research Ethics Committee (reference 0004).

\section{Measures}

Patients were sent the Minimum Asthma Assessment Tool $\left(\right.$ MAAT $^{29}$ ), a brief (two sides of A4) set of questionnaires developed from validated measures to identify patients with poor asthma control and potentially modifiable causes of poor control. This included:

i) The Asthma Control Questionnaire ${ }^{\mathrm{TM}}(\mathrm{ACQ})^{30}$ : a validated six-item questionnaire to assess asthma control over the past week. Items address: a) how frequently the patient was woken by their asthma; b) how bad their symptoms were when they woke up, c) how limited they were in their activities; d) how much shortness of breath they had; e) how much of the time they wheezed; and f) the average number of puffs of short-acting bronchodilator they used each day. Patients respond to each item on a 7point scale (0-6) and a mean score is calculated. Patients with a mean score of $\geq 1.5$ are considered to have poorly controlled asthma. ${ }^{31}$

ii) The Medication Adherence Report Scale (MARS). This short self-report measure of adherence has demonstrated good psychometric qualities in a range of illness groups, including asthma. ${ }^{32}$ Five items assess how participants use their preventer inhaler (e.g. "I forget to take my preventer inhaler", "I take my preventer inhaler less than instructed") on a five point Likert-type scale: "always"; "often"; "sometimes"; "rarely"; or "never". Those that report always or often engaging in one or more of the non-adherent behaviours are classified as low adherers.

iii) A single-item self-report measure of rhinitis and its impact was derived from the ARIA ${ }^{33}$ and IPCRG definition of rhinitis" : "Do you have any of these symptoms: itchy, runny, blocked nose or sneezing when you don't have a cold?" Patients were provided with five response options: "no"; "occasionally and little bother"; "occasionally but quite a bother"; "most days but little bother"; "most days and a lot of bother". Patients were classified as having severe rhinitis ("occasionally but quite a bother", "most days and a lot of bother"), mild rhinitis ("occasionally and little bother" and "most days but little bother") or no rhinitis ("no").

iv) A two-item self-report measure of smoking status was used: "Do you smoke?" ("Yes - current smoker", "exsmoker" or "never") and "How many cigarettes do you smoke per day?" (for current smokers). In addition, those who reported that they were current smokers were asked to indicate whether they would be willing to attend smoking cessation advice sessions ("yes"/"no").

\section{Statistical analysis}

All analyses were conducted using SPSS 12. There were three phases to the statistical analysis plan:

1) Descriptive statistics (means, frequencies) were used to explore sample characteristics.

2) Relationships between asthma control (ACQ scores) and clinical, demographic and self-report variables were explored using Pearson's correlation (age), Independent samples t-tests (gender, adherence), and one way ANOVAs with Tukey's post-hoc test (degree of rhinitis, smoking status).

3) Variables that were significantly associated with ACQ scores in Step 2 were entered into a multiple logistic regression to predict ACQ control.

\section{Results}

\section{Sample characteristics}

Of the 4429 patients involved in the asthma review, 3916 completed all sections of the questionnaire relevant to the analysis ( $88 \%$ completion rate). The mean age was 45 years (range 18-94) and 2313 (59\%) participants were female. 2199 (56\%) participants reported mild rhinitis and 924 (24\%) participants reported severe rhinitis. 671 (17\%) participants reported being current smokers. Of these, 341 (51\%) indicated that they would be willing to attend smoking cessation advice sessions. 1993 (51\%) participants reported that they always or often engaged in one or more non-adherent behaviours with their ICS and were classified as low adherers.

\section{Prevalence of poor control}

The distribution of ACQ scores is presented in Figure 1. 1474 (38\%) participants had ACQ scores of $\geq 1.5$, indicating that these 
J Clatworthy et al.

patients were highly likely to have poorly controlled asthma.

Relationship between demographic factors and asthma control

There was a significant positive correlation between ACQ scores and age, indicating that older age was associated with poorer asthma control $(r=.07, p<.001)$. There was no significant relationship between gender and asthma control $\left(\chi^{2}=.68, p=.41\right)$.

Relationship between self reported adherence and asthma control

As shown in Figure 2, participants reporting low adherence had significantly higher ACQ scores than those reporting high adherence $(t(3914)=6.15, p<.001)$.

Relationship between self reported degree of rhinitis and asthma control

Levels of control differed across reported rhinitis groups ( $F(2$,

\section{Figure 1. Distribution of ACQ scores.}

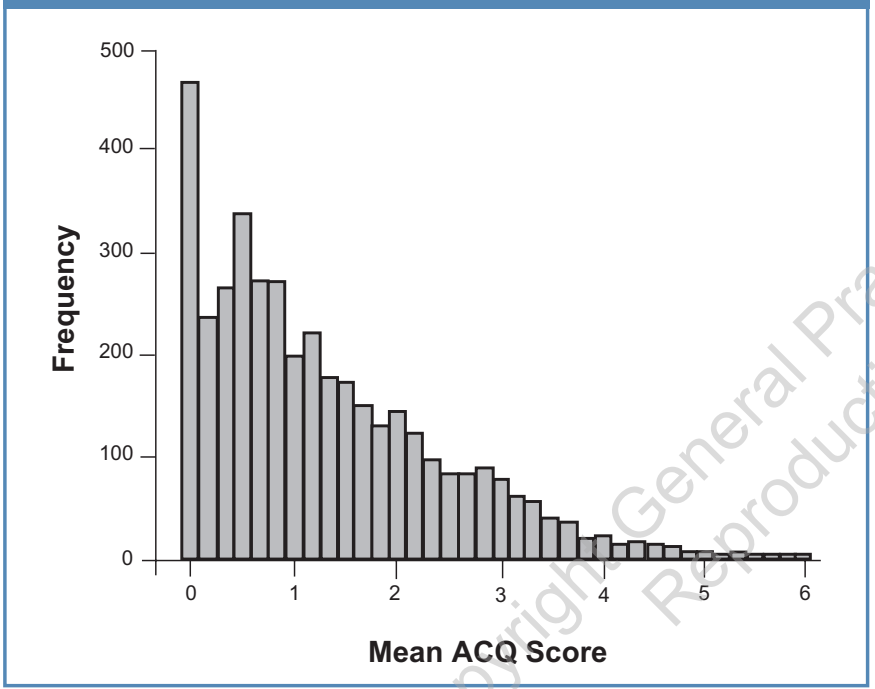

\section{Figure 3. Differences in ACQ scores across rhinitis} groups.

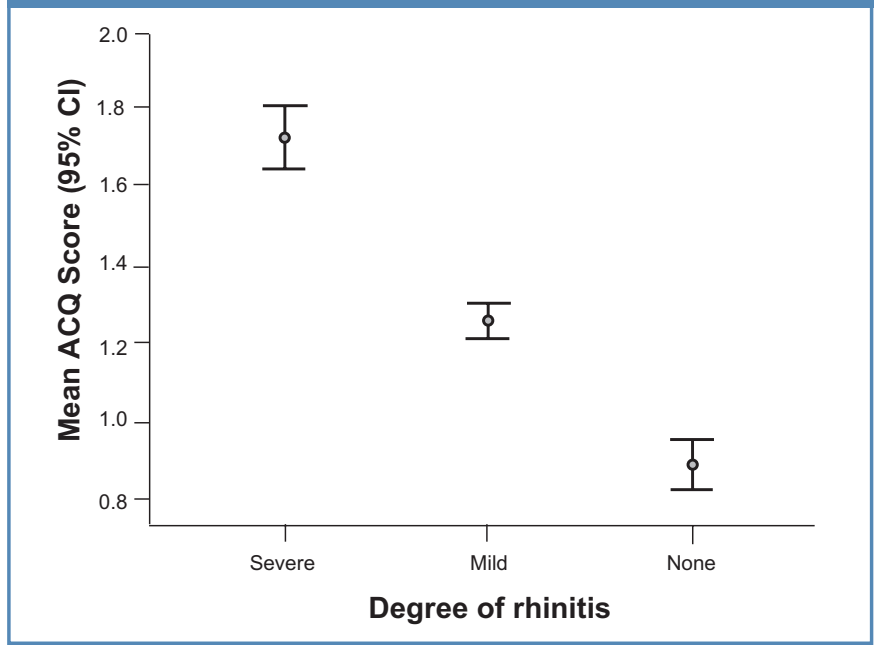

3913)=128.7, $p<.001)$; those reporting severe rhinitis had significantly higher $\mathrm{ACQ}$ scores than those reporting mild rhinitis, who in turn had significantly higher ACQ scores than those reporting no rhinitis (see Figure 3).

Relationship between smoking status and asthma control

As shown in Figure 4, non-smokers had significantly lower ACQ scores than ex-smokers, who had significantly lower ACQ scores than current smokers $(F(2,3913)=201.51$, $\mathrm{p}<.001)$. Among smokers, there was a significant relationship between the number of cigarettes smoked per day and asthma control $(F(5,655)=6.08, p<.001)$. Figure 5 illustrates this relationship, showing that the more cigarettes patients reported smoking each day, the worse their asthma control. Predicting poor asthma control

As shown in Table 1, multiple logistic regression revealed that

\section{Figure 2. Differences in ACQ scores between high and} low adherers (higher ACQ scores indicate poorer control).

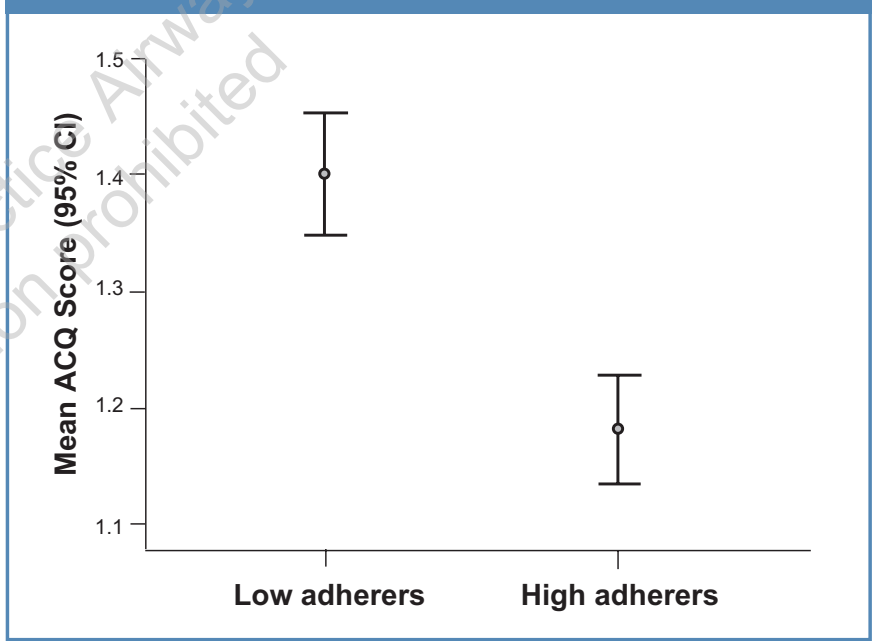

Figure 4. Differences in ACQ scores across smoking groups.

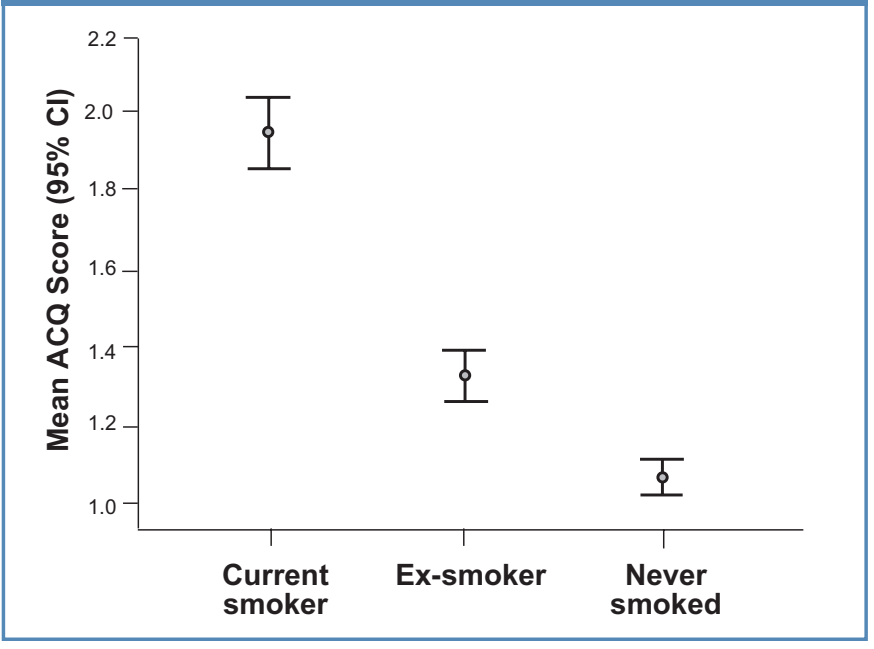




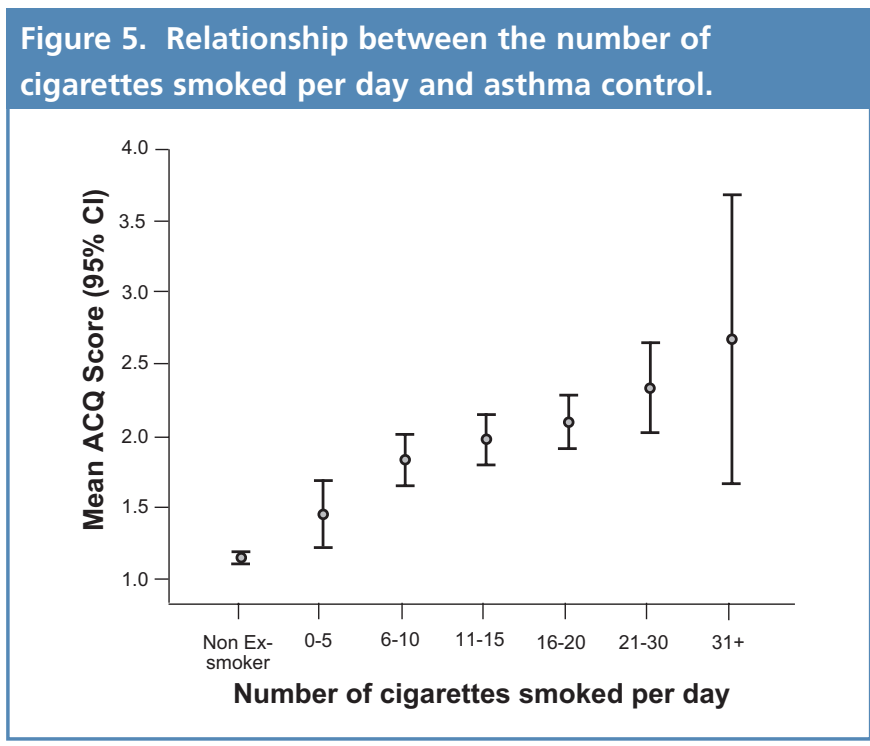

for every one year increase in age, the odds of having poorly controlled asthma increased by $1 \%$. Compared to those with no rhinitis, the odds of having poor control were more than doubled among those with mild rhinitis and more than quadrupled among those with severe rhinitis. Compared to non-smokers, the odds of poor asthma control were $60 \%$ higher among ex-smokers and were quadrupled among current smokers. Low adherers to ICS also had 35\% higher odds of having poor asthma control than high adherers.

\section{Discussion}

Three potentially modifiable predictors of poor asthma control were identified through the use of a simple, selfreport questionnaire; the degree of rhinitis, smoking status, and low adherence to medication. These predictors of poor asthma control were common in this sample; of the 1474 patients defined as having poorly controlled asthma (ACQ $\geq 1.5), 1158$ (79\%) reported that they smoked, had severe rhinitis and/or were non-adherent with their ICS medication. There is clearly scope to intervene to improve the quality of life of a significant number of people with poorly controlled asthma.

The relationship between rhinitis and asthma control is well documented in the literature. ${ }^{17,18}$ This study found that the degree of rhinitis reported was important, with those reporting severe rhinitis exhibiting the worst asthma control, followed by those reporting mild rhinitis and then those reporting no rhinitis symptoms; possible mechanisms are a correlation between the degree of upper and lower airways inflammation, or that upper airways inflammation acts as a driver to lower airways inflammation. ${ }^{34}$ There is some preliminary evidence to suggest that treatment of allergic rhinitis can improve asthma symptoms $s^{35-37}$ and guidelines recommend the treatment of concomitant rhinitis in asthma patients. ${ }^{34}$

\begin{tabular}{|c|c|c|c|c|}
\hline Variable & & OR & $95 \% \mathrm{Cl}$ & $\mathrm{p}$ \\
\hline Age & Years & 1.01 & $1.01-1.02$ & $<.001$ \\
\hline \multirow[t]{3}{*}{ Rhinitis } & Compared to no rhinitis: & & & \\
\hline & Significant rhinitis & 4.62 & $3.71-5.77$ & $<.001$ \\
\hline & Mild rhinitis & 2.09 & $1.72-2.54$ & $<.001$ \\
\hline \multirow[t]{3}{*}{ Smoking } & \multicolumn{4}{|l|}{ Compared to never smoking: } \\
\hline & Current smoker & 4.33 & $3.58-5.23$ & $<.001$ \\
\hline & Ex-smoker & 1.59 & $1.36-1.87$ & $<.001$ \\
\hline \multirow[t]{2}{*}{ Adherence } & Compared to high adherers: & & & \\
\hline & Low adherers & 1.35 & $1.18-1.55$ & $<.001$ \\
\hline
\end{tabular}

As expected based on previous research, ${ }^{26-28,38}$ patients who reported that they smoked had worse asthma control than non-smokers. The more cigarettes patients reported smoking each day the worse their asthma control. This may be because smoking reduces patients' sensitivity to the effects of Corticosteroids. ${ }^{25}$ In line with the findings of previous research, 39 the negative impact of smoking on asthma control appears to be at least partially reversible, as patients who had quit smoking reported significantly better asthma control than current smokers but not as good control as neversmokers. It is encouraging that $51 \%$ of smokers reported that they would be willing to attend smoking cessation advice sessions, highlighting the potential for improving asthma control in a large proportion of patients through a smoking cessation intervention. Indeed, GINA guidelines recommend that smoking cessation advice is offered to all asthma patients who smoke. ${ }^{40}$ Another potential reason for apparent poor asthma control among smokers is misdiagnosis of chronic obstructive pulmonary disease (COPD) as asthma. Research suggests that up to one third of smokers over the age of forty with an asthma diagnosis may in fact have COPD. ${ }^{41}$

Patients reporting low adherence to ICS had poorer asthma control than high adherers. Poor adherence may be unintentional (e.g. forgetting, misunderstanding instructions for use) or intentional (e.g. choosing not to take the medication on the basis of beliefs about asthma and its treatment). The types of beliefs associated with non-adherence to ICS include low perceived need for treatment ${ }^{32,42}$ (particularly likely when symptoms are not present or when patients do not believe the treatment is effective), and concerns about side effects or long term effects of treatment. ${ }^{32,43}$ One third of patients in this sample reported low adherence and could potentially benefit from intervention to address perceptual and practical barriers to adherence. 
In conclusion, there may be the potential to improve asthma control by increasing levels of adherence to ICS, treating concomitant rhinitis and facilitating smoking cessation. Trials are now needed to determine the extent to which these determinants of asthma control are indeed modifiable and to explore the impact of intervening on asthma control. The use of a brief, self-report questionnaire during asthma review would enable health care practitioners to identify current asthma control as well as those who may benefit from such interventions.

\section{Acknowledgements}

We are grateful to Julie von Ziegenweidt and Rhian Parham for their assistance with data processing/ analysis and to Elizabeth Juniper for permission to use the Asthma Control Questionnaire.

\section{Funding}

Data collection was funded by ALTANA Pharma and data analysis by Optimum Patient Care Ltd

\section{Conflict of interest}

DP has consultant arrangements with, Aerocrine, Boehringer Ingelheim, GlaxoSmithKline, Merck generics, Merck, Sharpe and Dohme, Schering-Plough and Teva. He or his team have received grants and research support for research in respiratory disease from the following organisations: UK National Health Service, Aerocrine, AstraZeneca, Boehringer Ingelheim, GlaxoSmithKline, Merck, Sharpe and Dohme, Novartis, Pfizer, Schering Plough and Teva. He has spoken for: Boehringer Ingelheim, GlaxoSmithKline, Merck, Sharpe and Dohme and Pfizer. He is director of Optimum Patient Care Ltd.

$\mathrm{RH}$ provides occasional consultancy and speaker services for pharmaceutical industry, including GlaxoSmithKline, Boehringer Ingelheim, Schering Plough, ALTANA Pharma and Merck, Sharpe and Dohme. His academic research in respiratory disease has been supported by grants from the National Institute for Health Research, Asthma UK, ALTANA Pharma, Boehringer Ingelheim GlaxoSmithKline and Schering Plough. He is director of Optimum Patient Care Ltd. JC has provided consultancy services for Optimum Patient Care Ltd.

DR has delivered lectures on behalf of and/or provided consultancy services to and lor received sponsorship from: AstraZeneca, GlaxoSmithKline,Novartis Pharma, Altana Pharma, Trinity Chiesi, Boehringer-Ingleheim, Ivax-Teva, MerckSharpeDohme, Alk-Abello, Pharmacia, UCB Pharma.

JH has provided occasional consultancy or speaker services for AstraZeneca, Merck, Sharpe and Dohme, Novartis and Teva.

\section{References}

1. BTS British Thoracic Society/Scottish Intercollegiate Guidelines Network. Guidelines on asthma management. Thorax 2003;58(suppl 1):i1-i94.

2. National Asthma Education and Prevention Program. Expert Panel Report 3: Guidelines for the diagnosis and management of asthma. Bethesda, Md: National Heart Lung and Blood Institute, National Institutes of Health; 2007.

3. Partridge MR, van der Molen T, Myrseth SE, Busse WW. Attitudes and actions of asthma patients on regular maintenance therapy: the INSPIRE study. BMC Pulm Med 2006;6(13).

4. Peters SP, Jones CA, Haselkorn T, Mink DR, Valacer DJ, Weiss ST. Real-world Evaluation of Asthma Control and Treatment (REACT): findings from a national Web-based survey. J Allergy Clin Immunol 2007;119(6):1454-61. http://dx.doi.org/10.1016/j.jaci.2007.03.022

5. Rabe KF, Vermeire PA, Soriano JB, Maier WC. Clinical management of asthma in 1999: the Asthma Insights and Reality in Europe (AIRE) study. Eur Respir J 2000;16(5):802-07.

6. Cazzoletti L, Marcon A, Janson C, et al. Asthma control in Europe: A real-world evaluation based on an international population-based study. J Allergy Clin
Immunol 2007;120(6):1360-7. http://dx.doi.org/10.1016/j.jaci.2007.09.019

7. Chen H, Gould MK, Blanc PD, et al. Asthma control, severity, and quality of life: quantifying the effect of uncontrolled disease. J Allergy Clin Immunol 2007;120(2):396-402. http://dx.doi.org/10.1016/j.jaci.2007.04.040

8. Lisspers K, Stallberg B, Hasselgren M, Johansson G, Svardsudd K. Quality of life and measures of asthma control in primary health care. J Asthma 2007;44(9):747-51. http://dx.doi.org/10.1080/02770900701645298

9. Lamb HM, Culy CR, Faulds D. Inhaled fluticasone propionate. A pharmacoeconomic review of its use in the management of asthma. Pharmacoeconomics 2000;18(5):487-510. http://dx.doi.org/10.2165/ 00019053-200018050-00008

10. Hoskins G, McCowan C, Neville RG, Thomas GE, Smith B, Silverman S. Risk factors and costs associated with an asthma attack. Thorax 2000;55(1):19-24. http://dx.doi.org/10.1136/thorax.55.1.19

11. Accordini S, Bugiani M, Arossa W, et al. Poor control increases the economic cost of asthma. A multicentre population-based study. Int Arch Allergy Immunol 2006;141(2):189-98. http://dx.doi.org/10.1159/000094898

12. Lane S, Molina J, Plusa T. An international observational prospective study to determine the cost of asthma exacerbations (COAX). Respir Med 2006;100(3):434-50. http://dx.doi.org/10.1016/j.rmed.2005.06.012

13. Horne R, Price D, Cleland J, et al. Can asthma control be improved by understanding the patient's perspective? BMC Pulm Med 2007;7:8. http://dx.doi.org/10.1186/1471-2466-7-8

14. Covar RA, Macomber BA, Szefler SJ. Medications as asthma triggers. Immunol Allergy Clin North Am 2005;25(1):169-90. http://dx.doi.org/10.1016/ j.iac.2004.09.009

15. Jenkins C, Costello J, Hodge L. Systematic review of prevalence of aspirin induced asthma and its implications for clinical practice. BMJ 2004;328(7437):434. http://dx.doi.org/10.1136/bmj.328.7437.434

16. Mascia K, Haselkorn T, Deniz YM, Miller DP, Bleecker ER, Borish L. Aspirin sensitivity and severity of asthma: evidence for irreversible airway obstruction in patients with severe or difficult-to-treat asthma. I Allergy Clin Immunol 2005;116(5):970-5. http://dx.doi.org/10.1016/j.jaci.2005.08.035

17. Thomas M, Kocevar VS, Zhang Q, Yin DD, Price D. Asthma-related health care resource use among asthmatic children with and without concomitant allergic rhinitis. Pediatrics 2005;115(1):129-34.

18. Koga T, Matsuse H, Kohrogi H, Kohno S, Aizawa H. Impact of Nasal Condition on Self-assessed Disease Control and Treatment Satisfaction in Patients with Asthma Complicated by Allergic Rhinitis. Allergol Int 2007;56(4):427-31. http://dx.doi.org/10.2332/allergolint.0-06-477

19. Shore SA. Obesity and asthma: implications for treatment. Curr Opin Pulm Med 2007;13(1):56-62. http://dx.doi.org/10.1097/MCP.0b013e3280110196

20. Yawn BP. Factors accounting for asthma variability: achieving optimal symptom control for individual patients. Prim Care Resp J 2008;17(3):138-47. http://dx.doi.org/10.3132/pcrj.2008.00004

21. Cochrane GM, Horne R, Chanez P. Compliance in asthma. Respiratory Medicine 1999;93(11):763-9. http://dx.doi.org/10.1016/S0954-6111(99)90260-3

22. Stern L, Berman J, Lumry W, et al. Medication compliance and disease exacerbation in patients with asthma: a retrospective study of managed care data. Ann Allergy Asthma Immunol 2006;97(3):402-08.

23. Blaiss MS. Part II: Inhaler technique and adherence to therapy. Curr Med Res Opin 2007;23 Suppl 3:S13-20. http://dx.doi.org/10.1185/030079907X226168

24. Barnes PJ. Introduction: how can we improve asthma management? Curr Med Res Opin 2005;21 Suppl 4:S1-3. http://dx.doi.org/10.1185/030079905X61712

25. Livingston $E$, Chaudhuri R, McMahon AD, Fraser I, McSharry CP, Thomson NC. Systemic sensitivity to corticosteroids in smokers with asthma. Eur Respir $J$ 2007;29(1):64-71. http://dx.doi.org/10.1183/09031936.06.00120505

26. Tomlinson JE, McMahon AD, Chaudhuri R, Thompson JM, Wood SF, Thomson NC. Efficacy of low and high dose inhaled corticosteroid in smokers versus non-smokers with mild asthma. Thorax 2005;60(4):282-7. 
http://dx.doi.org/10.1136/thx.2004.033688

27. Eisner MD, Iribarren $C$. The influence of cigarette smoking on adult asthma outcomes. Nicotine Tob Res 2007;9(1):53-6. http://dx.doi.org/ 10.1080/14622200601078293

28. Lazarus SC, Chinchilli VM, Rollings NJ, et al. Smoking affects response to inhaled corticosteroids or leukotriene receptor antagonists in asthma. Am J Respir Crit Care Med 2007;175(8):783-90. http://dx.doi.org/ 10.1164/rccm.200511-17460C

29. Horne R, Musgrave S, Lee A, Price D. The Minimal Asthma Assessment Tool (MAAT): a new method for prioritising patients for primary care review by identifying poor asthma control and the causes of poor control. General Practice Airways Group Annual Scientific Conference. Crewe, UK July 2005.

30. Juniper EF, O'Byrne PM, Guyatt GH, Ferrie PJ, King DR. Development and validation of a questionnaire to measure asthma control. Eur Respir $J$ 1999;14(4):902-07.

31. Juniper EF, Bousquet J, Abetz L, Bateman ED. Identifying 'well-controlled' and 'not well-controlled' asthma using the Asthma Control Questionnaire. Respir Med 2006;100(4):616-21. http://dx.doi.org/10.1016/j.rmed.2005.08.012

32. Horne R, Weinman J. Self regulation and self management in asthma: Exploring the role of illness perceptions and treatment beliefs in explaining nonadherence to preventer medication. Psychology and Health 2002;17(1):17-32. http://dx.doi.org/10.1080/08870440290001502

33. Bousquet J, Van Cauwenberge $P$, Khaltaev N. Allergic rhinitis and its impact on asthma. J Allergy Clin Immunol 2001;108(5 Suppl):S147-334. http://dx.doi.org/10.1067/mai.2001.118891

34. Price D, Bond C, Bouchard J, et al. International Primary Care Respiratory Group (IPCRG) Guidelines: Management of allergic rhinitis. Prim Care Resp J 2006;15:58-70. http://dx.doi.org/10.1016/j.pcrj.2005.11.002

35. Corren J, Manning BE, Thompson SF, Hennessy S, Strom BL. Rhinitis therapy and the prevention of hospital care for asthma: a case-control study. J Allergy
Clin Immunol 2004;113(3):415-19. http://dx.doi.org/10.1016/ j.jaci.2003.11.034

36. Stelmach R, do Patrocinio TNM, Ribeiro M, Cukier A. Effect of treating allergic rhinitis with corticosteroids in patients with mild-to-moderate persistent asthma. Chest 2005;128(5):3140-7. http://dx.doi.org/10.1378/ chest.128.5.3140

37. Price DB, Swern A, Tozzi CA, Philip G, Polos P. Effect of montelukast on lung function in asthma patients with allergic rhinitis: analysis from the COMPACT trial. Allergy 2006;61(6):737-42. http://dx.doi.org/10.1111/j.13989995.2006.01007.x

38. Thomson NC, Shepherd M, Spears M, Chaudhuri R. Corticosteroid insensitivity in smokers with asthma : clinical evidence, mechanisms, and management. Treat Respir Med 2006;5(6):467-81. http://dx.doi.org/10.2165/00151829200605060-00010

39. Chaudhuri R, Livingston E, McMahon AD, Thomson L, Borland W, Thomson NC. Cigarette smoking impairs the therapeutic response to oral corticosteroids in chronic asthma. Am J Respir Crit Care Med 2003;168(11):1308-11. http://dx.doi.org/10.1164/rccm.200304-5030C

40. Global Initiative for Asthma (GINA). Global Strategy for Asthma Management and Prevention. 2007; Available from: http://www.ginasthma.com

41. Tinkelman DG, Price DB, Nordyke RJ, Halbert RJ. Misdiagnosis of COPD and asthma in primary care patients 40 years of age and over. J Asthma 2006;43(1):75-80. http://dx.doi.org/10.1080/02770900500448738

42. Halm EA, Mora P, Leventhal $H$. No symptoms, no asthma: the acute episodic disease belief is associated with poor self-management among inner-city adults with persistent asthma. Chest 2006;129(3):573-80. http://dx.doi.org/10.1378/chest.129.3.573

43. Menckeberg TT, Bouvy ML, Bracke $M$, et al. Beliefs about medicines predict refill adherence to inhaled corticosteroids. J Psychosom Res 2008;64(1):47-54. http://dx.doi.org/10.1016/j.jpsychores.2007.07.016

Available online at http://www.thepcrj.org 